\title{
SOME OBSERVATIONS ON THE PATHOGENESIS AND NATURAL HISTORY OF INTRACRANIAL ANEURYSMS
}

\author{
BY
}

\section{T. CRAWFORD}

From the Departments of Pathology and Neurosurgery, St. George's Hospital and Medical School, London

The purpose of this paper is to present an account of the development of intracranial aneurysms and to describe the way in which they grow and rupture. It is hoped that this account and the coloured illustrations which accompany it will be of interest and use to the clinicians and radiologists working in this field who cannot obtain such a good view of the lesions as can the pathologist.

The observations which follow are based on the personal dissection, using a simple dissecting microscope, of 163 ruptured cerebral aneurysms and of some 40 unruptured aneurysms. The photographs have been made by using the macro-attachment for the Vicker's projection photomicrography equipment, with Kodak "ektachrome" as the colour film. The specimens, after careful cleaning under the dissecting microscope, were suspended across a metal ring by threads attached to the arteries and were illuminated by oblique incident beams from below, and the photographs taken at linear magnifications varying between three and eight times. Depth of focus was obtained by cutting down the lens aperture to $f 22$ and increasing exposure time accordingly. This method of illumination may give an unpleasant irregular lighting to the background, but this aesthetic blemish is amply repaid by the detailed delineation of the contours of the subject which are obtained.

The aneurysms which form this series have all arisen in close relationship to the angles of branching and anastomosis in, or close to, the circle of Willis. The distribution of the ruptured aneurysms is listed in Table $\mathrm{I}$.

In 20 instances $(12 \cdot 3 \%$ of the cases) a second unruptured aneurysm was present. Only with aneurysms arising in the angle between the posterior communicating artery and the internal carotid artery, which were four times more common on the right than on the left side, was any significant difference between the two sides found.

\section{Natural History of the Aneurysms}

The aneurysms originate from one of the junctional angles in which the circle of Willis and adjacent
TABLE I

DISTRIBUTION OF RUPTURED ANEURYSMS

\begin{tabular}{|c|c|c|c|}
\hline \multicolumn{2}{|c|}{ Anterior communicating artery } & & \multirow{3}{*}{$\begin{array}{l}46(28.2 \%) \\
20(12.3 \%)\end{array}$} \\
\hline Anterior cerebral arter & y & & \\
\hline Proximal part & $\cdots$ & 4 & \\
\hline Distal part .. & $\cdots$ & 16 & \multirow{4}{*}{$54(33.7 \%)$} \\
\hline Middle cerebral artery & $\cdots$ & & \\
\hline Origin & $\cdots$ & i4 & \\
\hline Main division & $\cdots$ & 34 & \\
\hline Distal & $\cdots \quad \cdots$ & 6 & \\
\hline \multicolumn{4}{|c|}{ Internal carotid at posterior communi- } \\
\hline cating artery ... & . $\quad \ldots$ & & \multirow{3}{*}{$30(18.4 \%)$} \\
\hline Right side .. & $\cdots$ & $\ddot{2} \dot{4}$ & \\
\hline Left side & $\therefore$ & 6 & \\
\hline Basilar artery $\quad \ldots$ & 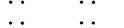 & . & \multirow{5}{*}{$\begin{array}{l}7(4 \cdot 3 \%) \\
3 \\
1 \\
1 \\
1\end{array}$} \\
\hline Posterior cerebrail arter & 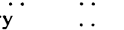 & $\ddot{\cdots}$ & \\
\hline Vertebral artery. .. & 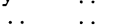 & $\cdots$ & \\
\hline Posterior inferior cereb & ellar artery & $\therefore$ & \\
\hline Left anterior choroidal & artery ... & . & \\
\hline \multicolumn{4}{|r|}{163} \\
\hline
\end{tabular}

vessels abound (Fig. 1). They are multiple in one eighth of the cases and when this occurs the common descriptive term, "berry aneurysm", is particularly appropriate (Fig. 2). In the case of the anterior communicating artery, which is often only 2 or $3 \mathrm{~mm}$. long, the aneurysm often involves the whole length of the artery (Fig. 3), though it may be more clearly arising at one end. Once started, the aneurysm tends to enlarge slowly but relentlessly: as it grows it commonly becomes irregular in shape, perhaps wrapping itself around adjacent vessels and nerves (Fig. 4), and in this way an aneurysm with quite a narrow neck may appear to have a broad origin from its parent vessel. As the aneurysms grow they often become bilocular (Fig. 5), but even those which remain grossly spherical or ovoid may show on closer scrutiny an appearance as of bubbles erupting from the surface (Fig. 6). It is evident that these "bubbles" are extremely thin-walled.

It is usually when the aneurysms have attained a diameter between 6 and $15 \mathrm{~mm}$. that clinical effects are produced, though it must be emphasized that many aneurysms never produce effects at all, while a few attain a much greater size and simulate tumours (Fig. 7). The one thing which may check the progressive enlargement of an aneurysm is the occurrence of extensive thrombosis within it (Fig. 8), 
and when this happens the aneurysm may appear much smaller in an arteriogram than it turns out to be at a subsequent operation or necropsy, or it may completely fail to fill.

Microscopic examination of the neck of an aneurysm (Fig. 8) shows that the muscle coat of the artery ceases abruptly at the point of origin, but the elastic lamina may sometimes extend some little distance into the body. At the fundus the wall comprises only an attenuated layer of hyaline fibrous tissue which merges imperceptibly with the imperfectly organized thrombus in the cavity, and on the outside fuses with the meninges or with any other anatomical structure on which it may impinge.

\section{Leakage and Rupture of Aneurysms}

There is probably no useful purpose to be served in attempting to distinguish between the leaking or "weeping" of a berry aneurysm and its frank rupture. Microscopic examination of the thinnedout fundus of an aneurysm sometimes shows a thin smear of fibrin with a few entangled blood cells on the outside, the appearance suggesting permeation of these elements through the wall: but in practice, if an aneurysm has bled significantly then a rupture is present, though this may vary from a minute pinhole to disruption of the whole aneurysm, with parallel variation in the clinical features.

Aneurysms usually rupture when they have reached a diameter of 6 to $15 \mathrm{~mm}$. but occasionally they burst when they are quite minute. When this happens, the appearance may be almost as if the hole had developed directly in the artery (Fig. 9) and the clinical course is likely to be of a fulminating character.

The 163 ruptured aneurysms listed in Table I have been carefully studied to determine the precise part of the aneurysmal sac at which rupture has occurred. Dividing the wall between the fundal pole and the neck into equal thirds, the rupture was classified as fundal if it occurred in the distal third, lateral in the middle third, and cervical in the proximal third; while, if for some reason, such as obscuring of the original state by operative procedures or damage at necropsy, the location of the rupture could not be confidently stated, the site of rupture was put down as undetermined. The findings are given in Table II and it will be seen that at least $64 \%$ of all

TABLE II

SITE OF RUPTURE FOR 163 CEREBRAL ANEURYSMS

\begin{tabular}{c|c}
\hline Site of Rupture & No. of Aneurysms \\
\hline Fundal segment & $105(64 \%)$ \\
Lateral segment & $17(10 \%)$ \\
Cervical segment & $3(2 \%)$ \\
Undetermined & $38(24 \%)$ \\
\hline
\end{tabular}

aneurysms and $105(84 \%)$ out of 125 for which the site could be determined, ruptured at the fundus.

A typical example of fundal rupture is illustrated in Fig. 10, while Fig. 11 shows a lateral rupture and Fig. 12 the only cervical rupture which it has proved possible to photograph. (There is technical difficulty in mounting for photography aneurysms which rupture at the neck, as the tear tends to extend and the aneurysm separates from its parent vessel.) Sometimes recurring episodes of haemorrhage and thrombosis occur at a single point of rupture. This results in a craggy, ulcer-like lesion with everted edges formed of successive layers of blood clot, while the neighbouring tissues acquire the characteristic golden colour of haemosiderin (Fig. 13).

The importance of the above observation on the frequency of fundal, as opposed to lateral and cervical rupture, lies in its application to surgical treatment. With present techniques, the most satisfying surgical procedure for ruptured aneurysm is the placing of a clip across the neck (Fig. 14) and this can clearly apply only when the rupture is distally situated. It may, therefore, be reassuring to the neurosurgeon to learn that there is a high probability - approximately three chances in fourof any aneurysm he approaches having its rupture at the fundus, and only a small possibility - of the order of one in 30 - of the tear being at the neck.

Serial sectioning of ruptured aneurysms reveals that the rupture often occurs by the bursting of one of the bubbles referred to above (Figs. 2, 4, and 6), but in aneurysms which contain considerable amounts of thrombus, the break is effected by blood dissecting up between the thrombus and the wall until it reaches the fundus, where these structures merge in ill-defined degenerate collagen-like layers, through which the burst takes place.

\section{Pathogenesis}

The microscopic anatomy of the cerebral arteries reveals two features which render these arteries particularly prone to aneurysm formation: first the media, in which the main strength of an artery resides, is much thinner than in other vessels (such as coronary arteries) of comparable calibre; and second, although there is a well developed internal elastic lamina, the external elastic lamina is very poorly developed and may be altogether absent. Add to this the fact, first clearly emphasized by Forbus (1930), that developmental faults in the media, leaving gaps of varying size, occur quite commonly at the points of arterial junctions, and the heavy responsibility thrown on the internal elastic lamina for maintaining the arterial wall will be appreciated. The occurrence of these medial faults has now been fully confirmed (Glynn, 1940) 


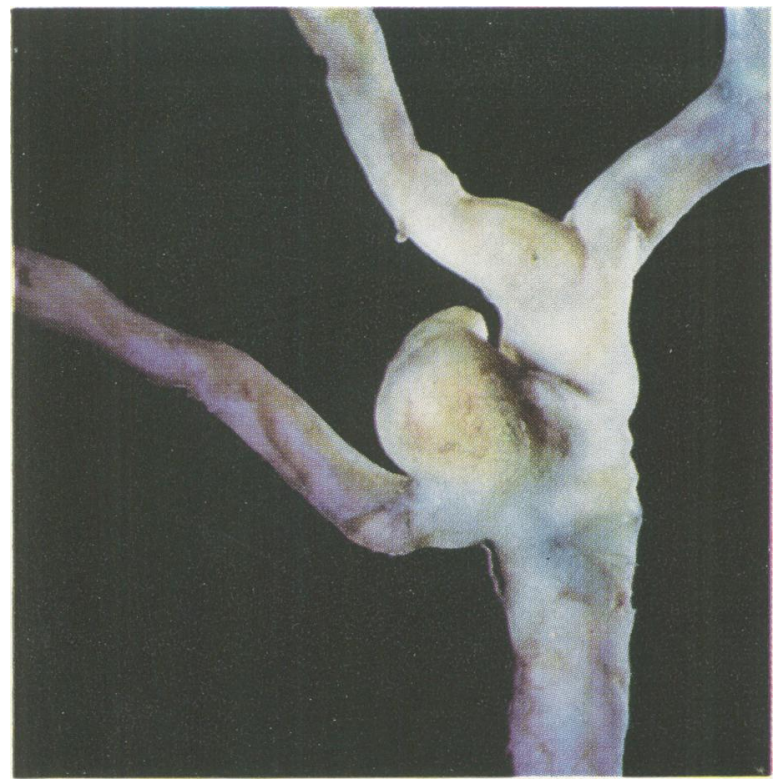

Fig. 1.-Typical berry aneurysm arising in the angle between the middle cerebral artery and a large branch. Large lipoid atheromatous plaques are present at the neck of the aneurysm and at the origin of the adjacent branch where there is some degree of dilatation.

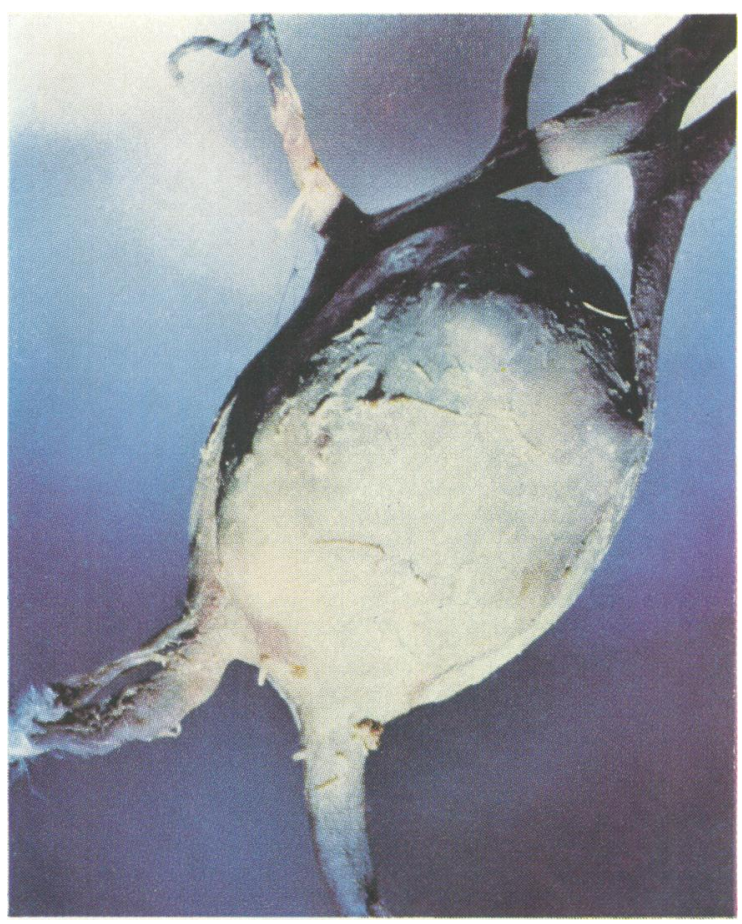

FIG. 3.-Aneurysm arising from the whole length of the anterior communicating artery. A second small communicating vessel joins the two anterior cerebral arteries just distal to the aneurysm.

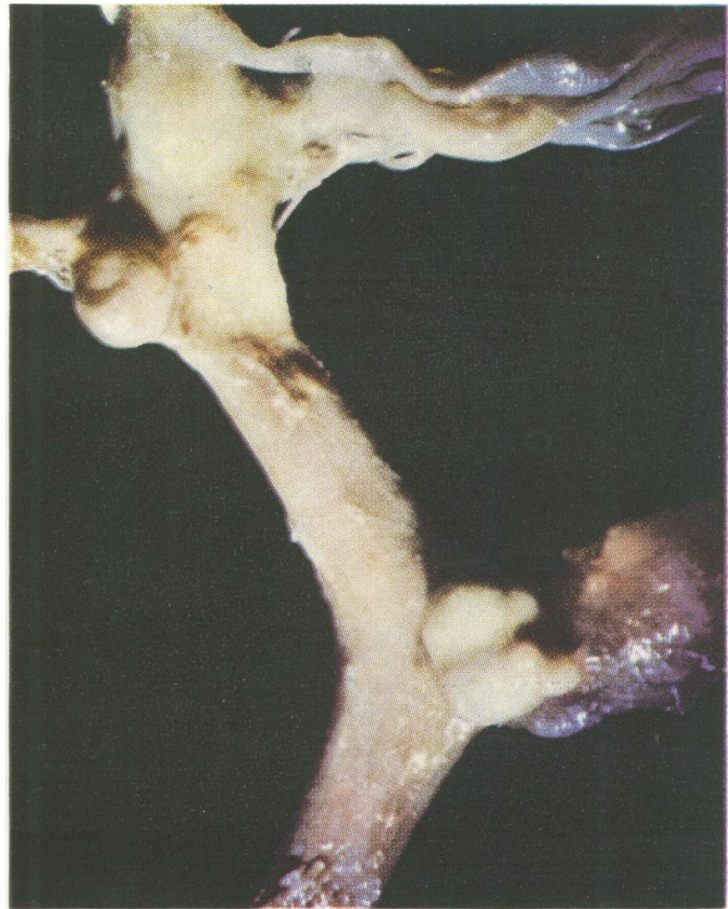

FIG. 2.-Two aneurysms arising at branches of a middle cerebral artery.

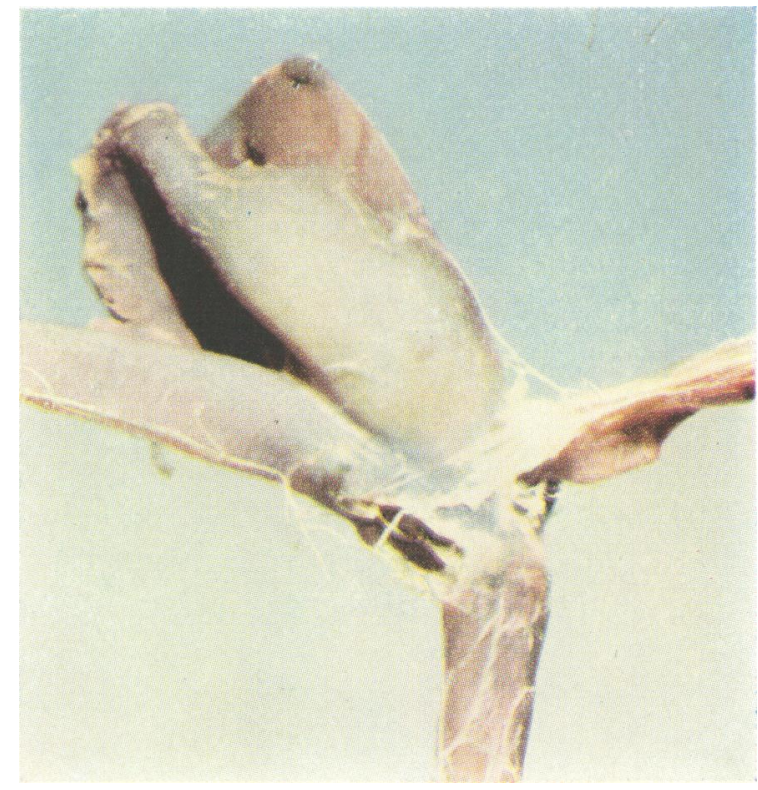

Fig. 4.-Middle cerebral artery aneurysm which had wrapped itself around the afferent trunk, giving a false impression of a broad origin. It has been partially dissected free. This aneurysm also shows a ruptured "bubble" at the fundus. 

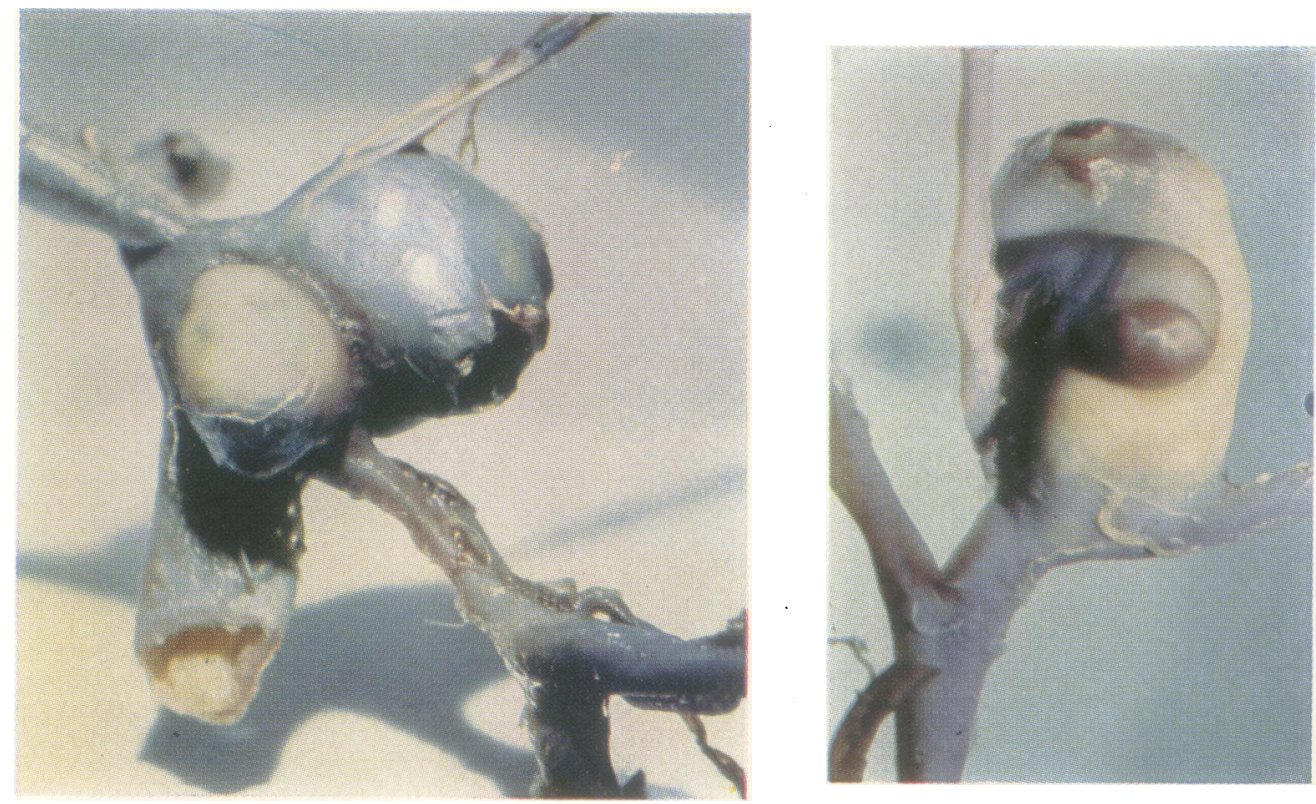

FIG. 6

FIG. 5
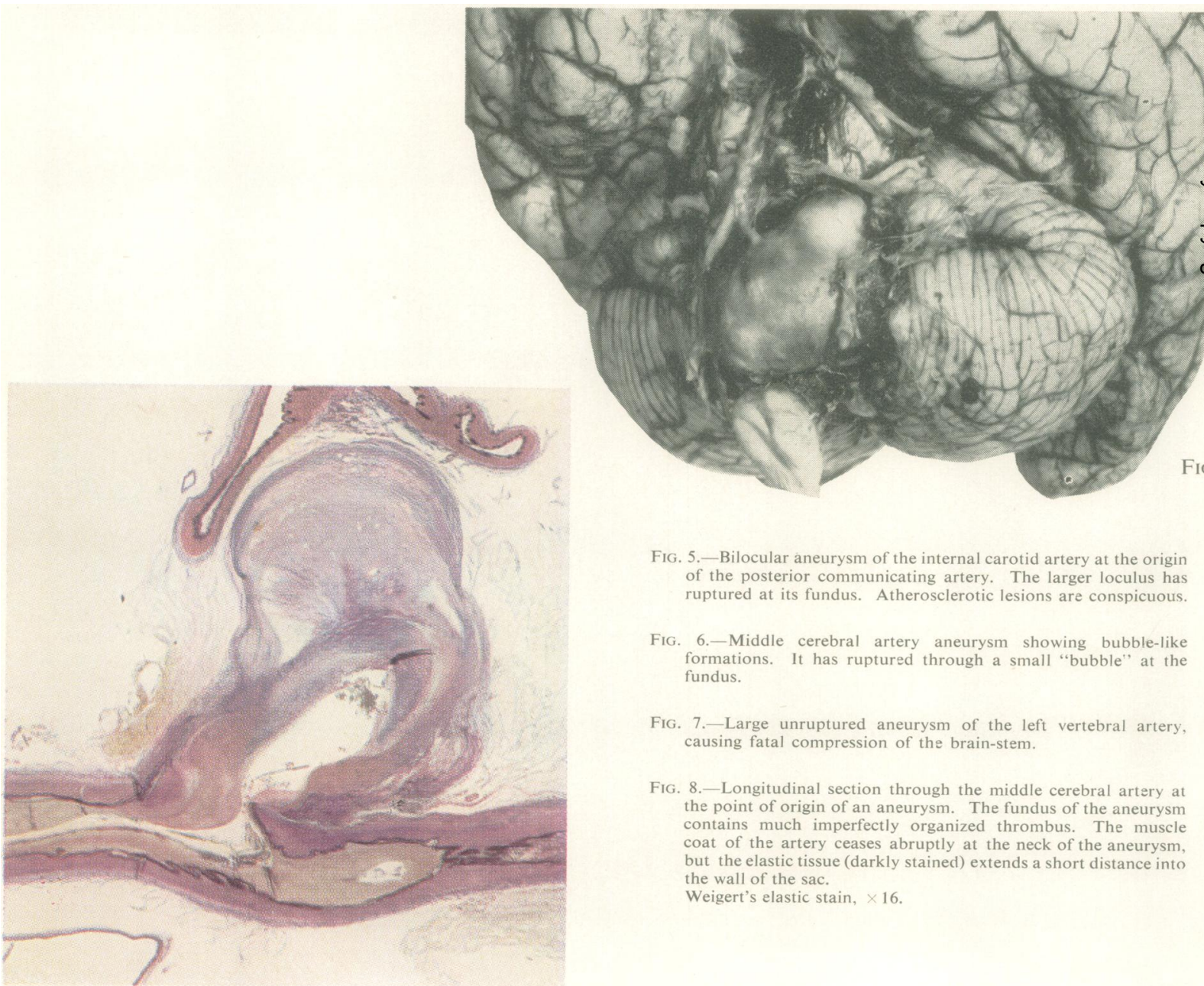

FIG. 5.-Bilocular aneurysm of the internal carotid artery at the origin of the posterior communicating artery. The larger loculus has ruptured at its fundus. Atherosclerotic lesions are conspicuous.

FIG. 6.-Middle cerebral artery aneurysm showing bubble-like formations. It has ruptured through a small "bubble" at the fundus.

FIG. 7.-Large unruptured aneurysm of the left vertebral artery. causing fatal compression of the brain-stem.

FIG. 8.-Longitudinal section through the middle cerebral artery at the point of origin of an aneurysm. The fundus of the aneurysm contains much imperfectly organized thrombus. The muscle coat of the artery ceases abruptly at the neck of the aneurysm. but the elastic tissue (darkly stained) extends a short distance into the wall of the sac.

Weigert's elastic stain, $\times 16$.

FIG. 8 


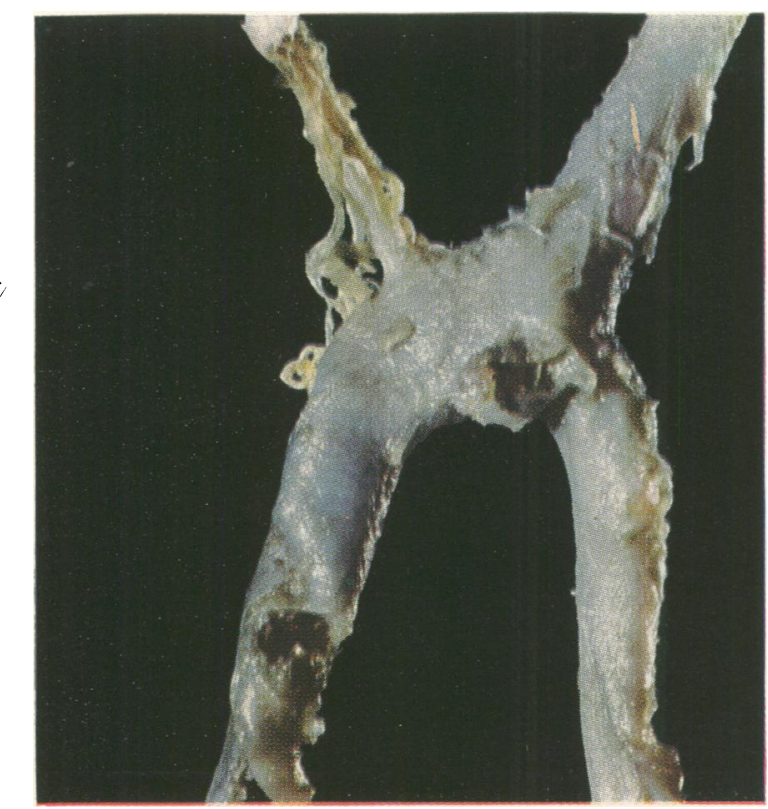

FIG. 9

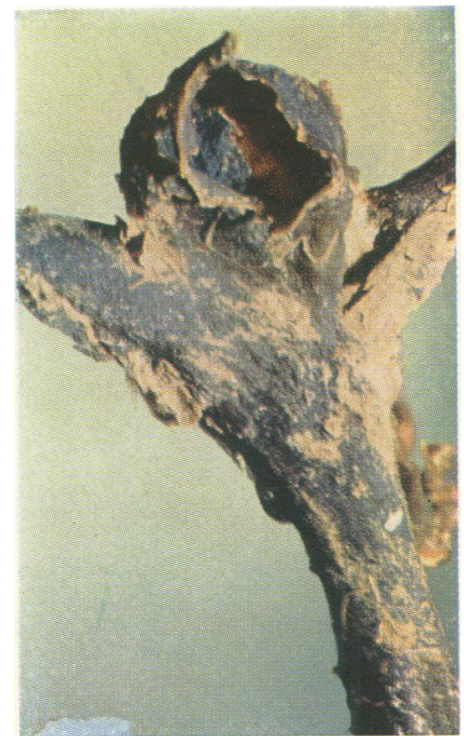

FIG. 11

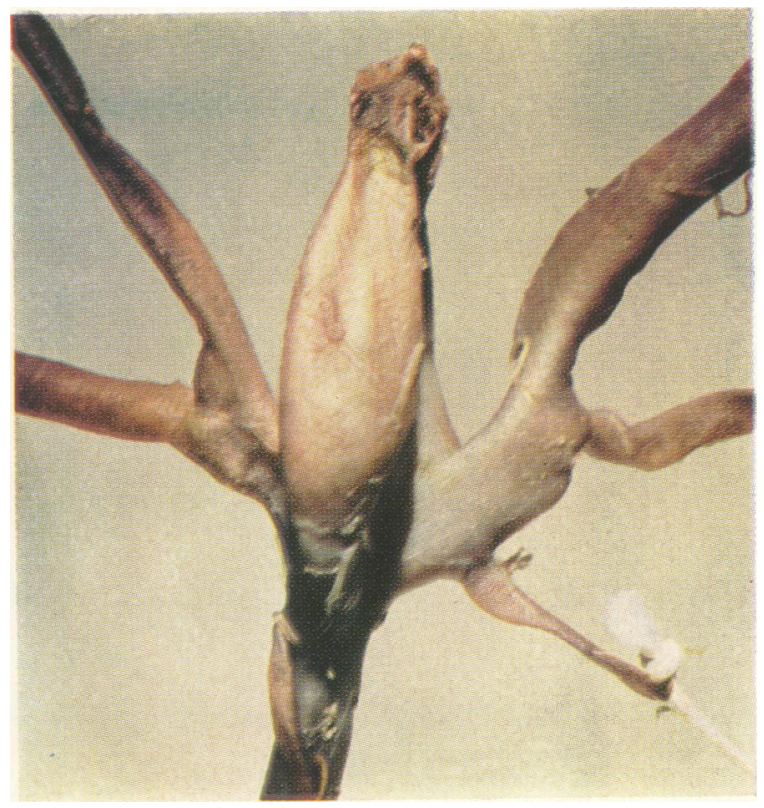

FIG. 10

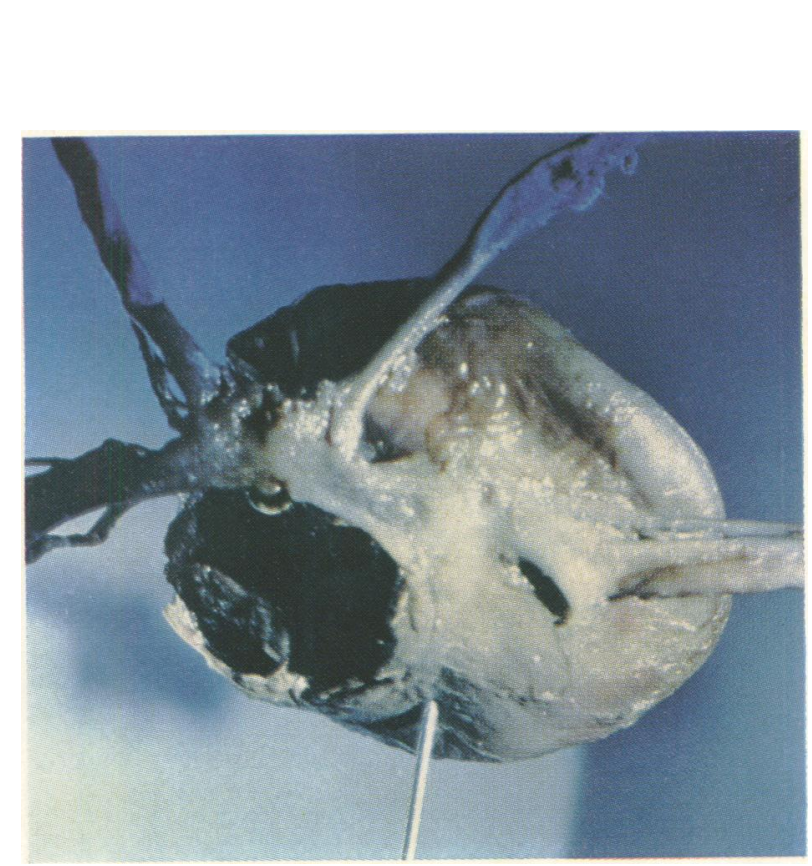

FIG. 12

FIG. 9.- Rupture of a minute aneurysm of the anterior communicating artery. The proximal part of the left artery is hypoplastic.

FIG. 10.-Typical example of an aneurysm at the first main bifurcation of the middle cerebral artery which has ruptured at the fundus.

FIG. 11.-Aneurysm at the bifurcation of the basilar artery, showing large lateral rupture.

FIG. 12.-Aneurysm of the middle cerebral artery which has ruptured at the neck. 


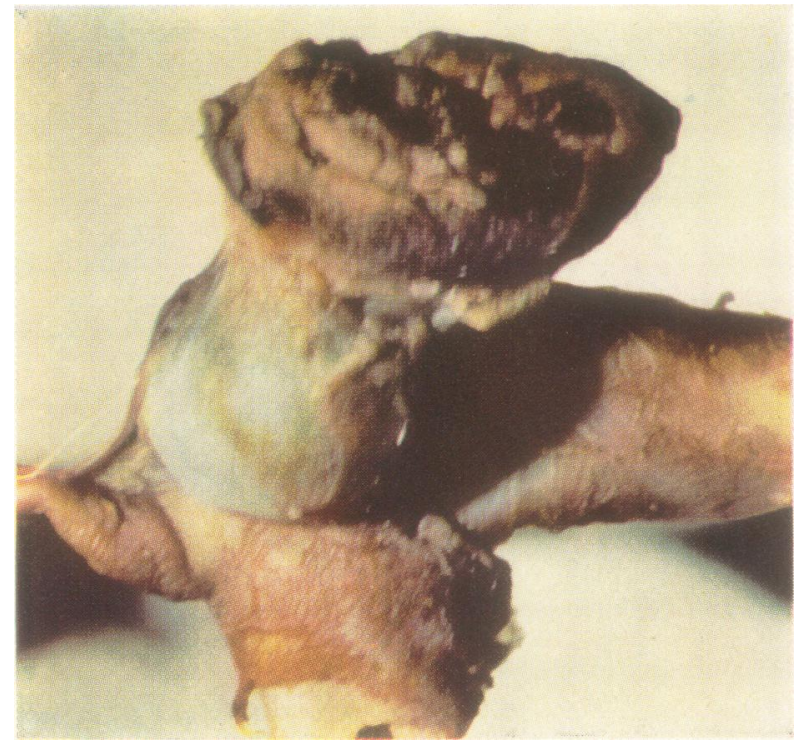

Fig. 13

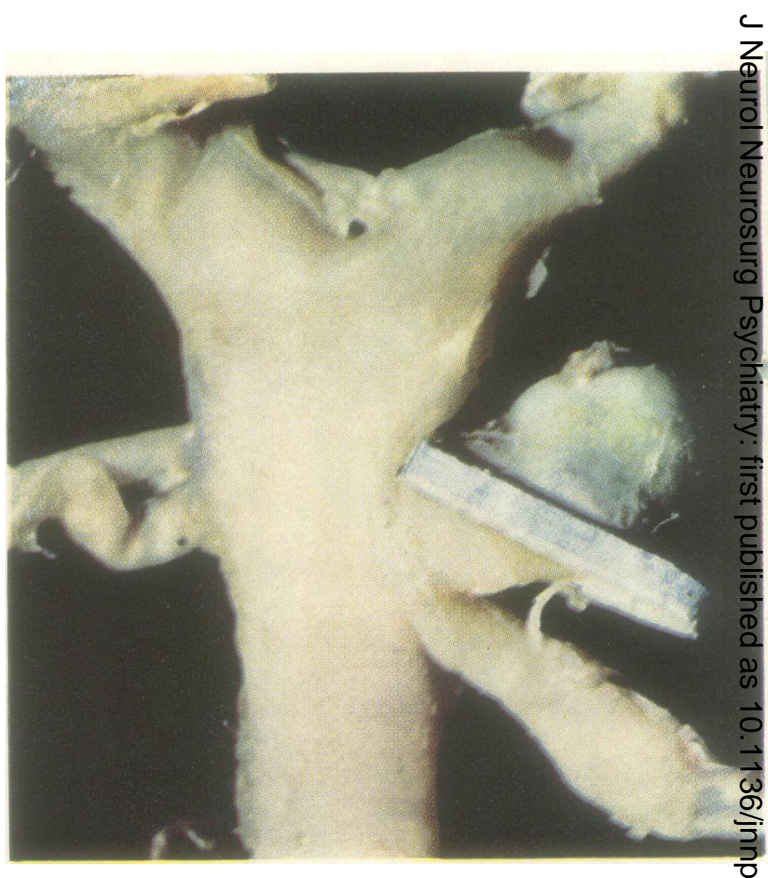

Fig. 14 ì

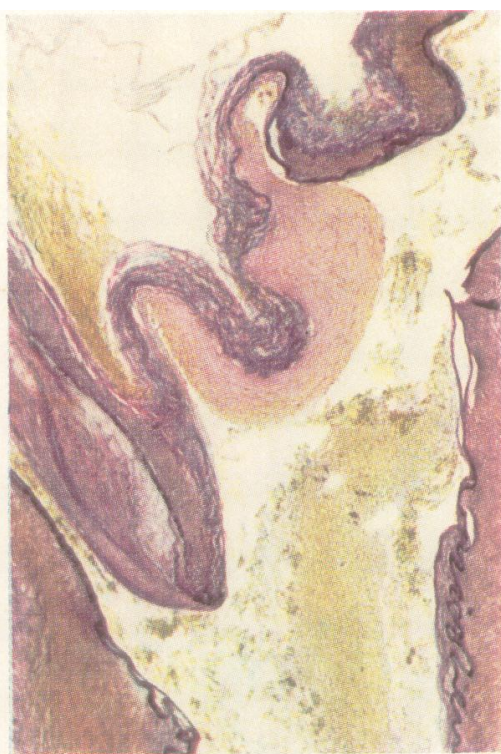

FIG. 16

FIG. 13.-Internal carotid artery aneurysm which has been the site of repeated haemorrhages through a fundal rupture. Thrombus is erupting through the burst and haemosiderin pigmentation is present in the adventitia of the adjacent vessels.

FIG. 14.-Aneurysm on the basilar artery at the origin of the superior cerebellar artery. The aneurysm has ruptured at the fundus and the neurosurgeon has placed a clip across the neck.

FIG. 15.-Longitudinal section through bifurcation of the middle cerebral artery showing a minute medial defect at the apex of the fork. Weigert's elastic stain, $\times 18$.

Fig. 16.-Similar section to the previous figure, but showing a very much larger medial fault. The intima is thickened at the site of the medial lesion. Weigert's elastic stain, $\times 25$

Fig. 17.-Frozen section showing the edge of an atheromatous plaque in the basilar artery. The internal elastic lamina is infiltrated with fat and is quite lost in the substance of the plaque. Haematoxylin and sudan IV $\times 40$.

FIG. 17 
and indeed their frequency has proved an embarrassment to those who would maintain that they are the essential causative lesions of the aneurysms. The faults, however, vary greatly in size, from tiny discontinuities of the muscle near the apex of the fork (Fig. 15) up to gaps of several millimetres in length (Fig. 16).

Two other factors come up for consideration in the production of these aneurysms, the blood pressure and atheromatous lesions in the vessels. The blood pressure is the distending force concerned and it must be clear that the normal blood pressure of early life may fail to produce an aneurysm through a small fault in the vessel wall, but succeed in doing this through a large one: and conversely, a small fault may resist distention by the normal blood pressure of early life, but yield before the higher blood pressures of middle age or before pathological hypertensive pressures.

Atherosclerosis is the remaining factor and its role has been stressed by Carmichael (1950) and by Walker and Allegre (1954). It is customary to emphasize the intimal lesion of atherosclerosis, and the medial changes which are a constant feature (Crawford and Levene, 1953) are often overlooked. These changes consist of localized medial thinning, down to almost complete disappearance in some cases, and in the cerebral arteries there is often extensive infiltration of the media with fat (Carmichael, 1950). More important in the present connexions, the internal elastic lamina also often degenerates at the base of an atheromatous plaque (Fig. 17). When the atheroma occurs at a site already weakened by a developmental fault, then the effect is likely to be additive and loss of the internal elastic lamina (the only significant source of strength at these points) may well result in aneurysmal dilatation. It is well known that severe atherosclerosis may be the sole pathogenetic factor in aneurysms of the abdominal aorta. The same may be true of fusiform aneurysms of the basilar artery (Fig. 18), and it is no surprise to find milder degrees of atheroma contributing to the pathogenesis of the commoner berry aneurysms. Evidence of a statistical character for the association between berry aneurysms and atherosclerosis is presented in Table III. In this table the frequency of severe coronary atheroma and its effects in the males aged $\mathbf{4 5}$ to $\mathbf{7 0}$ from the present

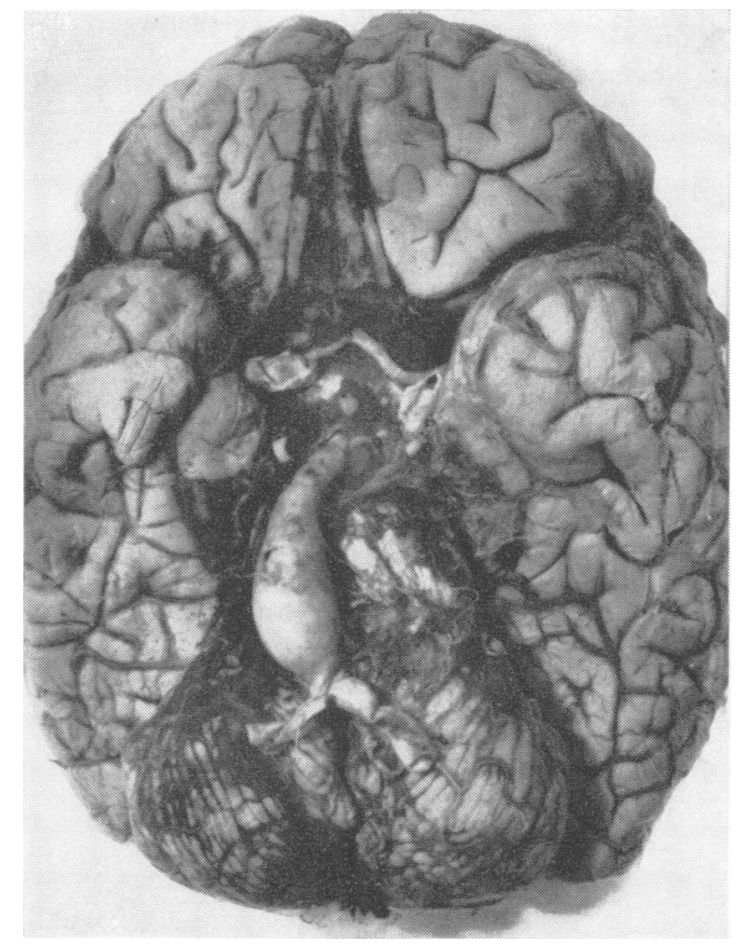

FIG. 18.-Atheromatous fusiform aneurysm of the basilar artery.

series of deaths from ruptured cerebral aneurysm is compared with the frequencies in men of the same age dying of causes not directly related to vascular disease. It will be seen that all the criteria of severe coronary atherosclerosis employed are from two to three times more frequent among victims of ruptured cerebral aneurysm than in the control group. (The control figures in Table III have been kindly provided by the Social Medicine Research Unit of the Medical Research Council from their national survey of necropsies in this age group (Morris and Crawford, 1958)).

An attempt to indicate the inter-relationships between the three pathogenetic factors in cerebral aneurysms occurring at different ages is made in Table IV. In this table the numbers are not intended to have precise mathematical significance, but to imply degrees for the various factors: thus, under

TABLE III

CORONARY ARTERY DISEASE IN MEN AGED 45 TO 70 YEARS DYING FROM RUPTURED CEREBRAL ANEURYSM

\begin{tabular}{|c|c|c|c|c|c|c|}
\hline & Total Cases & $\begin{array}{c}\text { Severe } \\
\text { Coronary } \\
\text { Atheroma }\end{array}$ & $\begin{array}{c}\text { Severe } \\
\text { Coronary } \\
\text { Stenosis }\end{array}$ & \begin{tabular}{|c|} 
Coronary \\
Calcification \\
Present
\end{tabular} & $\underbrace{}_{\substack{\text { Small } \\
\text { Scardial } \\
\text { Scars }}}$ & $\begin{array}{c}\text { Large } \\
\text { Myocardial } \\
\text { Scars }\end{array}$ \\
\hline $\begin{array}{l}\text { Deaths from primary ruptured cerebral aneurysm } \\
\text { Control deaths unrelated to vascular disease }\end{array}$ & $\begin{array}{r}49 \\
2,785\end{array}$ & $\begin{array}{l}44 \% \\
15 \%\end{array}$ & $16 \%$ & $28 \%$ & $5 \cdot 2 \%$ & $1.8 \%$ \\
\hline
\end{tabular}


TABLE IV

RELATIVE IMPORTANCE OF PATHOGENETIC FACTORS IN CEREBRAL ANEURYSMS AT DIFFERENT AGES

\begin{tabular}{l|c|c|c}
\hline & \multicolumn{3}{|c}{ Pathogenetic Factor } \\
\cline { 2 - 4 } \multicolumn{1}{c|}{ Age Group } & Medial Defect & Blood Pressure & Atherosclerosis \\
\hline $\begin{array}{l}\text { Childhood and } \\
\text { adolescence }\end{array}$ & $4^{*}$ & 1 & \\
$\begin{array}{l}\text { Early adult life } \\
\text { Middle age }\end{array}$ & $3=2$ & $1-3$ & 0 \\
Old age & $1-0$ & $2=4$ & $1=3$ \\
\hline
\end{tabular}

* For explanation see text.

the heading of medial defect, 0 indicates absence, 1 a trivial fault and 4 the largest faults; similarly 0 to 4 indicate absence of and degrees of severity of atherosclerosis, while under blood pressure, 1 and 2 imply physiological blood pressures of early and later life, while 3 and 4 indicate moderate and severe hypertension.

The extremes are represented by the aneurysms of childhood, when a large defect yields before the low normal blood pressure of that age and by the aneurysm of the elderly hypertensive atherosclerotic subject in which a medial defect plays no part, though the latter is likely to be of the fusiform rather than of the berry type. At intermediate ages all the factors are likely to be concerned in varying degrees.

\section{Summary}

A study of 163 ruptured berry aneurysms of the cerebral arteries is presented and the different types illustrated. The site of rupture is in the fundal segment in at least $64 \%$, while cervical rupture is uncommon. Pathogenesis is discussed: the three main factors-developmental faults in the media, atherosclerosis, and hypertension-play roles of varying importance according to the age at which the aneurysm develops.

I wish to thank Dr. Margaret D. Crawford of the M.R.C. Social Medicine Research Unit, The London Hospital, for drawing up Table III, and Professor J. N. Morris, Director of the Unit, for permission to use the control figures in that table.

Thanks are also due to the Board of Governors of St. George's Hospital for a grant to meet the expenses of this study and to the Wolfson Foundation for a contribution to the expenses of publication.

\section{REFERENCES}

Carmichael, R. (1950). J. Path. Bact., 62, 1.

Crawford, T., and Levene, C. I. (1953). Ibid. 66, 19.

Forbus, W. D̈. (1930). Bull. Johns Hopk. Hosp., 47, 239.

Glynn, L. E. (1940). J. Path. Bact., 51, 213.

Glynn, L. E. (1940). J. Path. Bact., 51,213. Walker, A. E., and Allegre, G. W. (1954). J. Neuropath. exp. Neurol.
$13,248$. 